\title{
Influence of Candida krusei and Candida glabrata on Candida albicans gene expression in in vitro biofilms
}

\author{
Patrícia Pimentel Barros*, Felipe Camargo Ribeiro, Rodnei Dennis Rossoni, \\ Juliana Campos Junqueira, Antonio Olavo Cardoso Jorge \\ Departament of Biosciences and Oral Diagnosis, Institute of Science and Technology, UNESP-Univ. Estadual Paulista, São José dos Campos, Brazil
}

\section{A R T I C L E I N F O}

\section{Article history:}

Received 5 May 2015

Received in revised form 17 December 2015

Accepted 12 January 2016

\section{Keywords:}

Yeast

Mixed biofilms

Virulence genes

Competitive interaction

\begin{abstract}
A B S T R A C T
Objective: The present study aimed to evaluate the interactions between the species Candida albicans, Candida krusei and Candida glabrata in monotypic and mixed biofilm models formed in vitro as well as the relative expression of the ALS1, ALS3, HWP1, BCR1, EFG1, TEC1, SAP5, PLB2 and LIP9 genes.

Material and methods: Mixed (C. albicans/C. krusei and C. albicans/C. glabrata) and monotypic biofilms were cultured for 0,12 and $24 \mathrm{~h}$. Gene expression was analyzed in the same biofilm model in which the number of $\mathrm{CFU} / \mathrm{mL}$ was counted.

Results: The C. albicans CFU/mL values were lower at the 12 and $24 \mathrm{~h}$ time points in the mixed biofilms compared with the monotypic biofilms, and decreases of $56.23 \%$ and $64.4 \%$ in C. albicans were observed when this species was associated with $C$. glabrata and C. krusei, respectively. In the presence of $C$. krusei, the expression of the ALS3, HWP1, BCR1, EFG1 and TEC1 genes of C. albicans was completely inhibited, indicating both transcriptome and the phenotypic antagonism between these two species, but genes related to the secretion of enzymes were stimulated. In the presence of $C$. glabrata, $C$. albicans showed a similar gene expression profile to that obtained in association with C. krusei, though it was altered to a lesser degree.

Conclusion: We conclude that C. krusei and C. glabrata may alter or inhibit the mechanisms involved in the in vitro adherence and formation of $C$. albicans biofilms, influencing the pathogenicity of this species and suggesting a competitive interaction with C. krusei and C. glabrata in biofilm formation.
\end{abstract}

(c) 2016 Elsevier Ltd. All rights reserved.

\section{Introduction}

The Candida genus can be found in approximately $25-75 \%$ of healthy individuals as a commensal organism, neither causing any apparent damage nor inducing inflammation in surrounding tissues. In fungal infections caused by these yeasts, Candida albicans is the predominant species found in the oral cavity of humans, representing $50-70 \%$ of clinical isolates (Hube, 2004; Mayer, Wilson, \& Hube, 2013). Recently, the incidence of infections by non-albicans species, especially Candida glabrata, Candida krusei, Candida parapsilosis and Candida tropicalis, has increased significantly. Junqueira et al. (2012) collected samples from the oral cavities of 60 HIV-positive patients and found that C. albicans was

\footnotetext{
* Corresponding author at: Departament of Biosciences Oral Diagnosis, Institute of Science and Technology, UNESP-Univ. Estadual Paulista, Av. Engenheiro Francisco José Longo 777, São José dos Campos CEP: 12245-000, SP, Brazil. Fax: +55 1239479010 .

E-mail addresses: barrosdnapp@yahoo.com.br, patricia.barros@ict.unesp.br (P.P. Barros).
}

the most prevalent species, representing approximately $51 \%$ of the isolates. In addition, $42 \%$ of these patients presented mixed Candida infections, formed by associations between $C$. albicans and C. krusei, C. albicans and C. glabrata, or C. albicans and C. tropicalis. Despite this increase in infections by non-albicans species, little is known about the ecological interactions between different species of this genus.

The study of microbial interactions in a given niche is extremely important for obtaining knowledge of the pathogenicity of microbes in the host and for the development of effective treatments without relapses. Few studies have evaluated the interactions between $C$. albicans and non-albicans species (Agwu et al., 2012; Cenci et al., 2008; El-Azizi, Starks, \& Khardori, 2004; Kirkpatrick, Lopez-Ribot, McAtee, \& Patterson, 2000; Thein, Samaranayake, \& Samaranayake, 2007; Thein, Seneviratne, Samaranayake, \& Samaranayake, 2009). According to Thein et al. (2007) high C. krusei concentrations are able to inhibit C. albicans in in vitro biofilm models, which reveals an antagonistic relationship between these two species. In contrast, Cenci et al. (2008) found no competitive relationship between $C$. albicans and C. glabrata in 
biofilms that formed on the surface of dental materials. Given that all of these studies were carried out by observing only phenotypic aspects of the interactions between Candida species, little is currently known about the behavior of $C$. albicans genes in the formation of mixed biofilms.

C. albicans exhibits specific disease development mechanisms that overcome the defenses and allow the colonization of mucosal tissue. The expression of $C$. albicans virulence factors may vary depending on the type of infection, whether local or systemic, the stage of the disease and the response of the host (Naglik et al., 2003). The ability to form biofilms in catheters and prostheses (abiotic) and on mucosal surfaces (biotic) is one of the most important characteristics of this species because it facilitates the adhesion, proliferation and the spreading of this microorganism to other infection sites. Biofilm formation is a complex sequential process that includes several stages: adhesion of yeast cells to a substrate, proliferation of these cells, the formation of hyphae on the most superficial layer of the biofilm, the production and accumulation of extracellular matrix and, ultimately, dispersion of these cells (Nobile and Mitchell, 2006).

Mature biofilms are far more resistant to antifungal therapy and immunological factors of the host compared with planktonic yeast cells (Fanning and Mitchell, 2012). The ability to form biofilms has been associated with the presence of transcriptional regulatory genes in C. albicans (Finkel and Mitchell, 2011). These genes include $B C R 1, T E C 1$ and EFG1. The ALS (agglutinin-like sequence) family of adhesins, which includes eight members (ALS1-ALS9) are expressed from $A L S$ genes encoding glycosylphosphatidylinositol (GPI)-anchored cell surface glycoproteins. Within this group, ALS3 is the most important gene because it actively contributes to biofilm formation and is positively regulated (highly expressed) during in vitro infection of epithelial cells of the oral mucosa (Murciano et al., 2012; Zordan \& Cormack, 2012). Other important proteins involved in the process of adhesion and invasion have been described in the literature, such as HWP1, EAP1, SSA1 and SAPS (Wächtler et al., 2001). Other C. albicans genes include proteases (SAPs), lipases (LIP) and phospholipases (PLBs), which contribute to colonization and infection via degrading components of the host cell membrane (Barros et al., 2008).

Because few studies have addressed the interactions between different species of the Candida genus and the importance of determining the specific mechanisms underlying the development of the disease and the high incidence of these lesions in immunocompromised patients, the aim of the present study was to evaluate the interactions between $C$. albicans, $C$. krusei and $C$. glabrata in monotypic and mixed biofilm models formed in vitro. Furthermore, we assessed the relative expression of the ALS1, ALS3, HWP1, BCR1, EFG1, TEC1, SAP5, PLB2, and LIP9 genes between these species.

\section{Materials and methods}

\subsection{Samples}

The samples used in the present study were isolated from a single HIV-infected patient with oropharyngeal candidiasis lesions induced by an association between $C$. albicans, $C$. krusei and $C$. glabrata. The samples were collected at the Emílio Ribas Infectious Diseases Institute (Instituto de Infectologia Emílio Ribas) under the approval of the Ethics Committee (Protocol 051/2009-PH/CEP) and were stored in the Microbiology Laboratory of the Institute of Science and Technology of São José dos Campos/São Paulo State University (Universidade Estadual Paulista “Júlio de Mesquita Filho"UNESP). The samples were grown in a chromogenic HiCrome Candida medium (Himedia, Mumbai, India), and the species they contained were identified using biochemical methods (API20C
System-BioMérieux, Paris, France) by Junqueira et al. (2012) and subsequently confirmed via molecular methods (PCR Multiplex).

\subsection{Biofilm formation}

Suspensions of each Candida sample were prepared from overnight cultures performed in $5 \mathrm{~mL}$ of YNB broth (Difco Laboratories Inc., Detroit, MI, USA) at $37^{\circ} \mathrm{C}$ for $18 \mathrm{~h}$. Subsequently, the cells were centrifuged at $2.000 \times g$ for $10 \mathrm{~min}$, and the supernatant was discarded. The pellet was resuspended in $0.9 \%$ $\mathrm{NaCl}$ and mixed in a tube mixer for $30 \mathrm{~s}$. The cells were washed two additional times. The cell densities were adjusted to $10^{7}$ viable cells/mL using a hemocytometer.

To form the monotypic and mixed biofilms, the methods described by Seneviratne, Silva, Jin, Samaranayake, and Samaranayake (2009) and Costa, Pereira, Freire, Junqueira, and Jorge (2013) were applied, with some modifications. Initially, $100 \mu \mathrm{L}$ of the standardized microorganism suspension was pipetted into the wells of 96-well microtiter plates (TPP ${ }^{\circledR}$, Trasadingen, Switzerland) to form monotypic biofilms, and $100 \mu \mathrm{L}$ of each species was used to form mixed biofilms. The plates were incubated with stirring at $75 \mathrm{rpm}$ (Quimis, Diadema, São Paulo) at $37^{\circ} \mathrm{C}$ for $90 \mathrm{~min}$ for the initial adhesion phase. After this period, the supernatant of the microorganism cultures was gently aspirated, and each well was rinsed with $200 \mu \mathrm{L}$ of sterile $0.9 \% \mathrm{NaCl}$ saline. The wells were washed two additional times with sterile $0.9 \% \mathrm{NaCl}$ saline to remove non-adherent cells. Subsequently, $200 \mu \mathrm{L}$ of YNB broth (Difco Laboratories Inc., Detroit, MI, USA) with $100 \mathrm{mM}$ glucose were pipetted into the wells, and the plates were incubated at $37^{\circ} \mathrm{C}$ for 0,12 or $24 \mathrm{~h}$ under stirring (Quimis, Diadema, São Paulo). For the $0 \mathrm{~h}$ time point, the biofilm was removed after the initial adhesion phase. The experiments were performed in triplicate at different times, with 10 repetitions, totaling 270 assays.

\subsection{Quantification of biofilm by viable cell count (CFU/mL)}

Following biofilm formation, the contents of the plates were aspirated and washed twice with sterile $0.9 \% \mathrm{NaCl}$ saline. Subsequently, $200 \mu \mathrm{L}$ of sterile $0.9 \% \mathrm{NaCl}$ saline was transferred to each well, and the biofilm adhered to the bottom of the plate was disrupted via homogenization for $30 \mathrm{~s}$ in an ultrasonic homogenizer (Vibra Cell-Sonics \& Materials, Inc., Newtown, USA) with $25 \%$ amplification. A $100-\mu \mathrm{L}$ volume of the inoculum was transferred to $1.5-\mathrm{mL}$ microtubes containing $900 \mu \mathrm{L}$ of sterile $0.9 \% \mathrm{NaCl}$ saline. From the solution obtained in the microtubes, decimal dilutions of the biofilm suspension were performed, and $100-\mu \mathrm{L}$ aliquots of these dilutions were inoculated into Petri dishes containing chromogenic HiCrome Candida medium (Himedia, Mumbai, India), followed by incubation of the plates at $37^{\circ} \mathrm{C}$ for $48 \mathrm{~h}$. After this time, the density of the yeast in $\mathrm{CFU} / \mathrm{mL}$ was calculated. The Candida species in the mixed biofilms were differentiated based on the color of the colony using HiCrome Candida medium: light green for $C$. albicans, off-white for $C$. glabrata and purple for C. krusei.

\subsection{Quantitative RT-PCR}

Total RNA was extracted using a TRIzol kit (Ambion, Inc., Carlsbad, CA, USA) as recommended by the manufacturer. A $1.0 \mathrm{~mL}$ volume of TRIzol was added to a $2.0-\mathrm{mL}$ microtube containing the collected yeast, followed by incubation at room temperature (RT) for $10 \mathrm{~min}$. Subsequently, $200 \mu \mathrm{L}$ of chloroform (Sigma-Aldrich, St. Louis, MO, USA) was added, and the microtubes were centrifuged at $12,000 \times \mathrm{g}$ for $15 \mathrm{~min}$ at $4{ }^{\circ} \mathrm{C}$. The supernatant was then transferred to a new microtube, and $500 \mu \mathrm{L}$ of isopropanol (Sigma-Aldrich, St. Louis, MO, USA) was added. After 
centrifugation, the obtained pellet was washed with 70\% ethanol (Sigma-Aldrich, St. Louis, MO, USA), centrifuged again and resuspended in $50 \mu \mathrm{L}$ of RNA Storage buffer (Ambion Inc., Carlsbad, CA, USA). The concentration, purity and quality of the RNA was verified using a NanoDrop 2000 spectrophotometer (Thermo Fisher Scientific Inc., Wilmington, DE, USA) and through agarose gel electrophoresis (Invitrogen ${ }^{\mathrm{TM}}$, Carlsbad, CA, USA) with staining using ethidium bromide (Invitrogen ${ }^{\mathrm{TM}}$, Carlsbad, CA, USA) and visualization on a transilluminator.

The extracted total RNA ( $2 \mu \mathrm{g}$ ) was treated with DNase I (Turbo DNase Treatment and Removal Reagents-Ambion Inc., Carlsbad, CA, USA) and transcribed into complementary DNA (cDNA) using the SuperScript ${ }^{\circledR}$ III First-Strand Synthesis SuperMix for qRT-PCR Kit (Invitrogen ${ }^{\mathrm{TM}}$, Carlsbad, CA, USA), according to the protocols recommended by the manufacturer.

The primers for all genes analyzed in the present study were described and used in the same way as indicated by Nailis, Coenye, Van Nieuwerburgh, Deforce, and Nelis (2006) and Nailis et al. (2010) and Hnisz, Bardet, Nobile, Petryshyn, and Glaser (2012). Their specificity was confirmed for C. albicans, and not for the other species of this genus.

The transcribed cDNAs were amplified for relative quantification of the expression of the EFG1, TEC1, BCR1, ALS1, ALS3, HWP1, SAP5, LIP9 and PLB2 genes in relation to the concentration of the reference gene (ACT1). In the present study, four reference genes, $A C T 1, P M A 1, R I P 1$ and $L S C 2$, were tested in all experimental groups. The obtained results were analyzed at http://www.leonxie.com/ referencegene.phpe, and the selected reference gene was ACT1.

The qPCR method was applied to evaluate the amount of the cDNA product in the exponential phase of the amplification reaction. As a detection system, the $S \mathrm{BR}^{\circledR}$ Green fluorophore (Platinum ${ }^{\circledR}$ SYBR $^{\circledR}$ Green qPCR SuperMix-UDG Applied Biosystems, Framingham, MA, USA) was used, in the following reaction mixture: $12.5 \mu \mathrm{L}$ of Super mix Platinum SYBR Green, $1 \mu \mathrm{L}$ of ROX (reference dye), $300 \mathrm{nM}$ of the forward primer, $300 \mathrm{nM}$ of the reverse primer, $3.4 \mu \mathrm{L}$ of cDNA solution (diluted $1: 5$ ) and $2.1 \mu \mathrm{L}$ of DEPEC water (Invitrogen ${ }^{\mathrm{TM}}$, Carlsbad, CA, USA), to obtain a final volume of $20 \mu \mathrm{L}$ in each well of a 96-well plate (Invitrogen ${ }^{\mathrm{TM}}$, Carlsbad, CA, USA). As a negative control for the reaction, all of the reagents were added to the last wells of the plates except for cDNA, and the wells were sealed with optical adhesive (Invitrogen ${ }^{\mathrm{TM}}$, Carlsbad, CA, USA). Subsequently, the plate was placed in a StepOnePlus $^{\text {TM }}$ System (Applied Biosystems, Framingham, MA, USA) device, and the following cycling parameters were used: $50^{\circ} \mathrm{C}$ for $2 \mathrm{~min}$, followed by an initial denaturation at $95^{\circ} \mathrm{C}$ for 2 min and 40 cycles of $95^{\circ} \mathrm{C}$ for $15 \mathrm{~s}$ and $60^{\circ} \mathrm{C}$ for $30 \mathrm{~s}$. After the end of the last cycle, the samples were subjected to dissociation (melting) curve analysis, and the absence of any bimodal curve or abnormal amplification signal was observed and analyzed every $0.1^{\circ} \mathrm{C}$. The $2^{-\Delta \Delta \mathrm{CT}}$ method was used to analyze the relative changes in gene expression from the quantitative RT-PCR experiment (Livak and Schmittgen, 2001).

\subsection{Statistical analysis}

The data are expressed as the means \pm standard deviation (SD) of the results obtained in each experimental group and for each time point of biofilm development and were analyzed for a normal distribution using the Kolmogorov-Smirnov test (SigmaPlot $^{\mathrm{TM}}$ Systat Software, Inc., San Jose, CA, USA). The data obtained in the $\mathrm{CFU} / \mathrm{mL}$ assay showed a normal distribution compared with the control ( $0 \mathrm{~h}$ time monotypic biofilm) and were analyzed using analysis of variance (ANOVA) and Tukey test. The statistical analysis was performed using GraphPad Prism software (GraphPad Software, Inc., California, CA, USA). P values $<0.05$ were considered significant (Tables 1 and 2).

\section{Results}

When counting the $\mathrm{CFU} / \mathrm{mL}$ of the yeast in biofilms formed in vitro at the 12 and $24 \mathrm{~h}$ time points, we observed that $C$. albicans showed higher $\mathrm{CFU} / \mathrm{mL}$ values in monotypic biofilms compared with mixed biofilms associated with C. krusei and C. glabrata (Fig. 1). These data suggest that $C$. albicans establishes competitive relationships with $C$. krusei and $C$. glabrata during biofilm formation. More specifically, when comparing the results obtained from mixed versus $C$. albicans monospecies biofilms, we observed reductions of $52.6 \%$ and $64.4 \%$ for $C$. albicans in association with $C$. krusei at 12 and $24 \mathrm{~h}$, respectively, while in association with $C$. glabrata, reductions of $69.8 \%$ and $56.23 \%$ were observed. The numbers of $\mathrm{CFU} / \mathrm{mL}$ in the $C$. albicans monotypic biofilms were $6.40 \pm 0.19,6.92 \pm 0.24$ and $6.77 \pm 0.09 \log _{10}$ for the 0,12 and $24 \mathrm{~h}$ time points of biofilm formation, respectively. Compared with the $0 \mathrm{~h}$ time point (control), the values obtained at 12 and $24 \mathrm{~h}$ showed significant differences $(p=0.001)$. In the presence of $C$. krusei, $6.39 \pm 0.14,6.72 \pm 0.16$ and $6.29 \pm 0.19 \mathrm{CFU} / \mathrm{mL}$ were recorded, and in the presence of $C$. glabrata, 6.24 $\pm 0.09,6.52 \pm 0.16$ and $6.39 \pm 0.14 \mathrm{CFU} / \mathrm{mL}$ were recorded at the 0,12 and $24 \mathrm{~h}$ time points, respectively. Significant values $(p=0.001)$ were found for the association with $C$. glabrata at $12 \mathrm{~h}$ and for those both with $C$. kruse $i$ and $C$. glabrata at $24 \mathrm{~h}(p=0.0182)$. There was also an increase in the $\mathrm{CFU} / \mathrm{mL}$ of $C$. albicans in both the monotypic and mixed biofilms observed at the $12 \mathrm{~h}$ time point, indicating that this yeast had reached the log phase of the growth curve.

For the analysis of gene expression, the primers employed in this study were specific for the targeted $C$. albicans genes, amplifying in the expected PCR fragment, which were subjected to agarose gel electrophoresis to confirm the molecular weight (Fig. 1-Supplementary material). The efficiency of PCR amplification was between $95 \%$ and $100 \%$ for each primer tested, indicating validation of the primers and the standardization of the qPCR assays. The analysis of the obtained melting curves confirmed the presence of a single peak, demonstrating the specificity of the tested primers.

Table 1

Values of relative quantification (Log) and standard deviation for all genes analyzed in monotypic and mixed biofilms of Candida albicans clinical strain 60 at 12 h.

\begin{tabular}{|c|c|c|c|c|c|c|c|c|c|}
\hline Groups & ALS1 & ALS3 & HWP1 & BCR1 & TEC1 & EFG1 & SAP5 & LIP9 & PLB2 \\
\hline Control & $1.0^{\mathrm{A}}$ & $1.0^{\mathrm{A}}$ & $1.0^{\mathrm{A}}$ & $1.0^{\mathrm{A}}$ & $1.0^{\mathrm{A}}$ & $1.0^{\mathrm{A}}$ & $1.0^{\mathrm{A}}$ & $1.0^{\mathrm{A}}$ & $1.0^{\mathrm{A}}$ \\
\hline $\mathrm{Ca} 12 \mathrm{~h}$ & $0.03 \pm 0.08^{\mathrm{B}}$ & $3.81 \pm 1.30^{\mathrm{B}}$ & $16.41 \pm 4.47^{\mathrm{B}}$ & $1.95 \pm 0.53^{\mathrm{B}}$ & $2.81 \pm 0.40^{\mathrm{B}}$ & $1.49 \pm 0.24^{\mathrm{B}}$ & $3.49 \pm 0.92^{\mathrm{B}}$ & $3.73 \pm 1.10^{\mathrm{B}}$ & $2.30 \pm 0.50^{\mathrm{B}}$ \\
\hline $\mathrm{Ca} / \mathrm{Ck} 12 \mathrm{~h}$ & $0.30 \pm 0.64^{C}$ & $0.07 \pm 0.26^{\mathrm{C}}$ & $0.13 \pm 0.68^{\mathrm{C}}$ & $0.23 \pm 0.32^{\mathrm{C}}$ & $0.23 \pm 0.03^{C}$ & $0.07 \pm 0.026^{C}$ & $9.45 \pm 3.99^{C}$ & $8.74 \pm 2.28^{C}$ & $2.99 \pm 1.03^{C}$ \\
\hline $\mathrm{Ca} / \mathrm{Cg} 12 \mathrm{~h}$ & $0.39 \pm 0.22^{\mathrm{D}}$ & $3.87 \pm 0.97^{\mathrm{D}}$ & $13.7 \pm 5.16^{\mathrm{D}}$ & $1.94 \pm 0.37^{\mathrm{D}}$ & $1.45 \pm 0.43^{D}$ & $0.86 \pm 0.16^{\mathrm{D}}$ & $18.75 \pm 3.15^{\mathrm{D}}$ & $2.06 \pm 0.70^{\mathrm{D}}$ & $3.89 \pm 1.16^{\mathrm{D}}$ \\
\hline
\end{tabular}

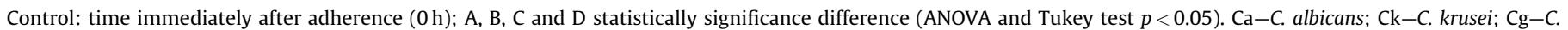
glabrata. 
Table 2

Values of relative quantification (Log) and standard deviation for all genes analyzed in monotypic and mixed biofilms of Candida albicans clinical strain 60 at $24 \mathrm{~h}$.

\begin{tabular}{|c|c|c|c|c|c|c|c|c|c|}
\hline Groups & ALS1 & ALS3 & HWP1 & $B C R 1$ & TEC1 & EFG1 & SAP5 & LIP9 & PLB2 \\
\hline Control & $1.0^{\mathrm{A}}$ & $1.0^{\mathrm{A}}$ & $1.0^{\mathrm{A}}$ & $1.0^{\mathrm{A}}$ & $1.0^{\mathrm{A}}$ & $1.0^{\mathrm{A}}$ & $1.0^{\mathrm{A}}$ & $1.0^{\mathrm{A}}$ & $1.0^{\mathrm{A}}$ \\
\hline $\mathrm{Ca} 24 \mathrm{~h}$ & $0.45 \pm 0.10^{\mathrm{B}}$ & $2.82 \pm 1.11^{\mathrm{B}}$ & $27.59 \pm 1.81^{B}$ & $1.64 \pm 0.35^{\mathrm{B}}$ & $0.87 \pm 0.19^{\mathrm{A}}$ & $0.69 \pm 0.05^{\mathrm{B}}$ & $14.86 \pm 2.9^{\mathrm{B}}$ & $2.40 \pm 0.51^{\mathrm{B}}$ & $1.30 \pm 0.28^{\mathrm{B}}$ \\
\hline $\mathrm{Ca} / \mathrm{Ck} 24 \mathrm{~h}$ & $0.96 \pm 0.34^{\mathrm{A}}$ & $0.15 \pm 0.05^{\mathrm{C}}$ & $0.19 \pm 0.85^{C}$ & $0.90 \pm 0.32^{\mathrm{A}}$ & $1.03 \pm 0.23^{\mathrm{A}}$ & $0.22 \pm 0.04^{C}$ & $6.33 \pm 3.0^{C}$ & $6.89 \pm 1.96^{C}$ & $3.04 \pm 0.57^{C}$ \\
\hline $\mathrm{Ca} / \mathrm{Cg} 24 \mathrm{~h}$ & $0.27 \pm 0.07^{C}$ & $1.36 \pm 0.86^{\mathrm{A}}$ & $5.28 \pm 1.21^{\mathrm{D}}$ & $0.44 \pm 0.16^{\mathrm{C}}$ & $0.26 \pm 0.48^{\mathrm{B}}$ & $0.18 \pm 0.05^{\mathrm{D}}$ & $10.36 \pm 3.8^{\mathrm{D}}$ & $4.60 \pm 1.20^{\mathrm{D}}$ & $2.55 \pm 0.44^{\mathrm{D}}$ \\
\hline
\end{tabular}

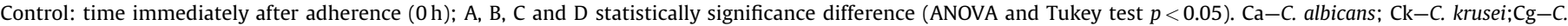
glabrata.

The expression levels of adhesion genes (ALS1, ALS3 and HWP1), transcriptional regulatory genes (TEC1, BCR1 and EFG1), and hydrolase genes (SAP5, PLB2 and LIP9) were quantified in cells from the Ca60 sample at the 0,12 and $24 \mathrm{~h}$ time points during the development of monotypic and mixed biofilms using quantitative real-time PCR (qPCR), as shown in Figs. 2-4 .

In the association with $C$. krusei, the ALS1, ALS3, HWP1 and EFG1 genes were downregulated; however, the SAP5, PLB2 and LIP9 genes were upregulated at 12 and $24 \mathrm{~h}$, showing significant differences $(p=0.001)$ compared with control. The TEC1 and BCR1 genes were also downregulated, but these differences were significant only at the $12 \mathrm{~h}$ time point. Among all of analyzed genes, ALS3 and HWP1 were the most downregulated genes in the presence of $C$. krusei, in agreement with the results obtained for the $\mathrm{CFU} / \mathrm{mL}$ counts in the present study, which suggests that $C$. krusei affects the adhesion of $C$. albicans during biofilm formation and reduces the development of $C$. albicans filamentation.

In the association with C. glabrata, the ALS3, HWP1, SAP5, PLB2 and LIP9 genes were upregulated at 12 and $24 \mathrm{~h}$, and the TEC1 and $B C R 1$ genes were upregulated only at $12 \mathrm{~h}$ compared with the control. All of the values were significant $(p=0.001)$. The ALS1 and EFG1 genes were downregulated at 12 and $24 \mathrm{~h}$, and the TEC1 and $B C R 1$ genes were downregulated at $24 \mathrm{~h}$; all values were significant. Most of the $C$. albicans genes analyzed in the present study were stimulated in the presence of $C$. glabrata, in agreement with the results obtained for the $\mathrm{CFU} / \mathrm{mL}$ counts, as the reduction of $C$. albicans was smaller in the presence of $C$. glabrata compared with C. krusei.

\section{Discussion}

In nature, biofilms are generally composed of a multitude of microbial species. This is particularly true of the oral cavity, where more than 200 microbial species coexist in a unique habitat. Candida species are oral commensals found in $50-60 \%$ of the population either as transient or permanent colonizers (Samaranayake, 2006). Oral carriage of more than one yeast species is relatively frequent. For instance, Samaranayake, MacFarlane, and Williamson (1987) in a pioneering study showed an incidence of $15 \%$ multiple species Candida carriage intraorally in a cohort of dental hospital patients. Subsequent workers have also shown that multispecies Candida colonization is becoming an increasing problem especially in debilitated patients with malignancies and bone marrow transplant recipients and those with candidemia (Agwu et al., 2012; Cenci et al., 2008; Junqueira et al., 2012; Thein et al., 2007, 2009). This study is unprecedented in the literature because we evaluate the interaction of different Candida species in biofilm formation and confirmed with gene expression at different times.

The present study evaluated the influence of $C$. krusei and C. glabrata when associated with C. albicans on a model of in vitro biofilm production at 12 and $24 \mathrm{~h}$ based on CFU/mL counts and quantification of the ALS1, ALS3, HWP1, BCR1, EFG1, TEC1, SAP5, PLB2, and LIP9 genes of $C$. albicans, which contribute to the development of diseases and to protection against host defenses, allowing the invasion and destruction of colonized tissue.

Regarding the obtained $C$. albicans $\mathrm{CFU} / \mathrm{mL}$ counts, higher $\mathrm{CFU} / \mathrm{mL}$ values were obtained at $12 \mathrm{~h}$ in all groups compared with the 0 and $24 \mathrm{~h}$ time points. These findings coincide with a study by Thein et al. (2007), wherein the authors analyzed the quantity of the biofilm formed, based on CFU/mL counts, on acrylic surfaces during the interaction between $C$. albicans and $C$. krusei at time points of $0,3,6,9$ and $12 \mathrm{~h}$, observing the greatest growth at $12 \mathrm{~h}$. Chandra et al. (2001) temporally analyzed the ultrastructure of C. albicans biofilms formed in test specimens and defined three distinct phases of development. These authors observed the highest biomass production between 12 and $30 \mathrm{~h}$, classifying this period as the intermediate stage in biofilm production.

In polymicrobial biofilms formed by fungi and bacteria, microbial diversity may directly influence the survival and proliferation of microorganisms (Morales and Hogan, 2010; Park, Han, Park, Choi, \& Lee, 2014). These interactions may be beneficial for the microorganisms. For example, mixed biofilms containing $C$. albicans and Streptococcus spp. are more resistant to antimicrobial agents (Martin, Wächtle, Schaller, Wilson, \& Hube, 2011) conversely; there are also antagonistic interactions, in which one species is impaired in relation to another. A clear example of such antagonism is the interaction between $C$. albicans and Pseudomonas aeruginosa, wherein the latter accumulates on the filaments of the yeast, feeding on the hyphae, and consequently causing the death of $C$. albicans (Hogan, Vik, \& Kolter, 2004). The first reports of an interaction between two types of Candida were published by Kirkpatrick et al. (2000), who demonstrated that the association between $C$. albicans and $C$. dubliniensis, in both planktonic cells and biofilms, was antagonistic because the growth of both species was impaired. One of the most probable causes of such an effect would be competition between these species for nutrients and inhibition by toxic products generated from the metabolism of one species, preventing the growth of the other.

The present study is the first to report the inhibitory influence of $C$. krusei on the expression of the ALS1, ALS3, HWP1, BCR1, EFG1 and TEC1 genes of $C$. albicans during in vitro biofilm production. The presence of $C$. krusei during the in vitro development of a C. albicans biofilm resulted in an inhibitory and antagonistic relationship, which was observed based not only on a decrease in $\mathrm{CFU} / \mathrm{mL}$ counts in mixed biofilms but also on the reduced expression of genes related to adherence and transcriptional regulation of the biofilm formation process. In the present study, reductions of $52.6 \%$ and $64.4 \%$ in the C. albicans count were observed at the 12 and $24 \mathrm{~h}$ time points. This antagonism between these two species agrees with the findings of Thein et al. (2007), who studied the in vitro interaction between $C$. albicans and C. krusei and observed competition between these two species, including an $85 \%$ 
A

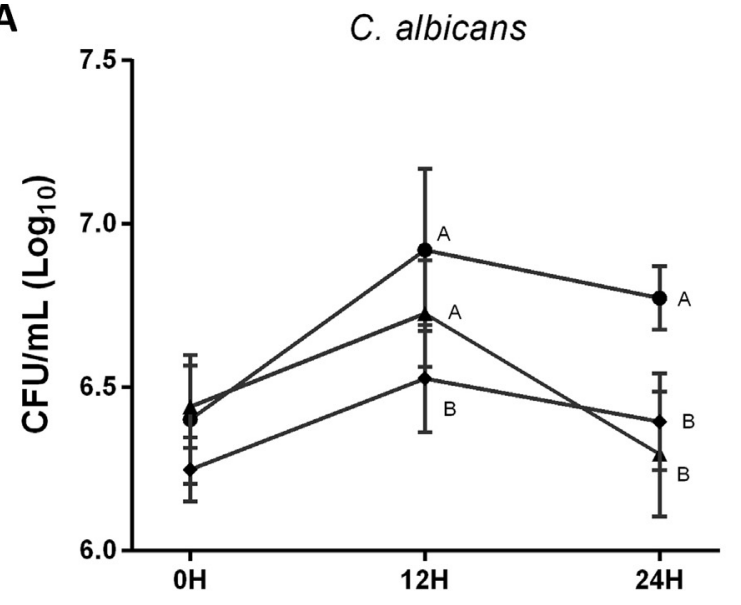

$\rightarrow$ Monotypic

$\neq$ Heterotypic with C. krusei

Heterotypic with C. glabrata

B

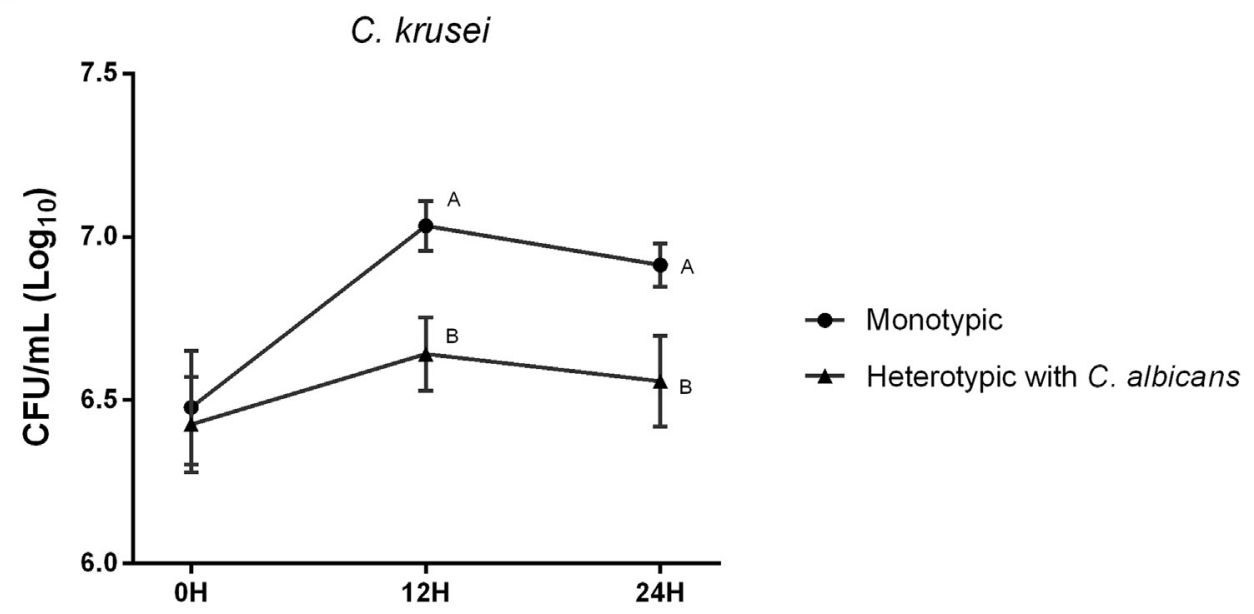

C

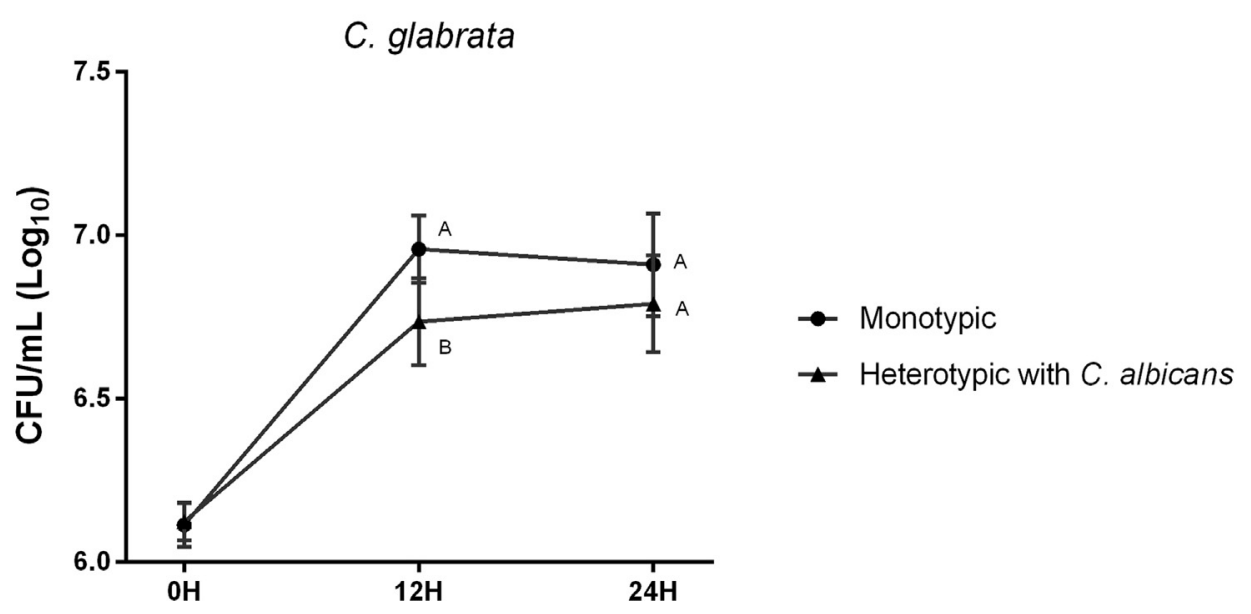

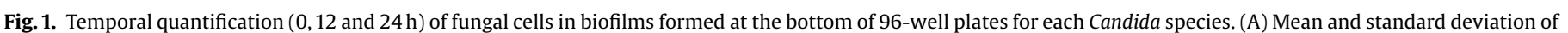

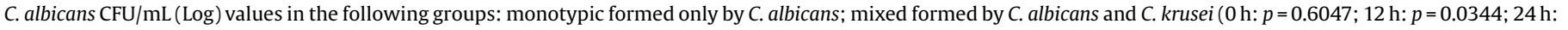

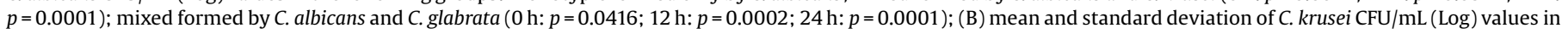

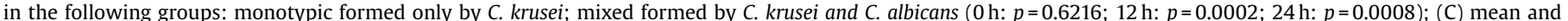

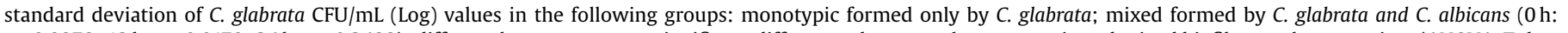

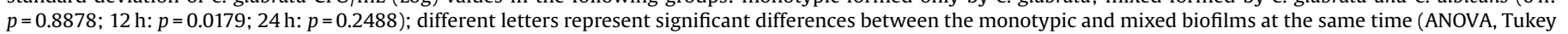
test, student $t$ test, $p<0.05$ ). 

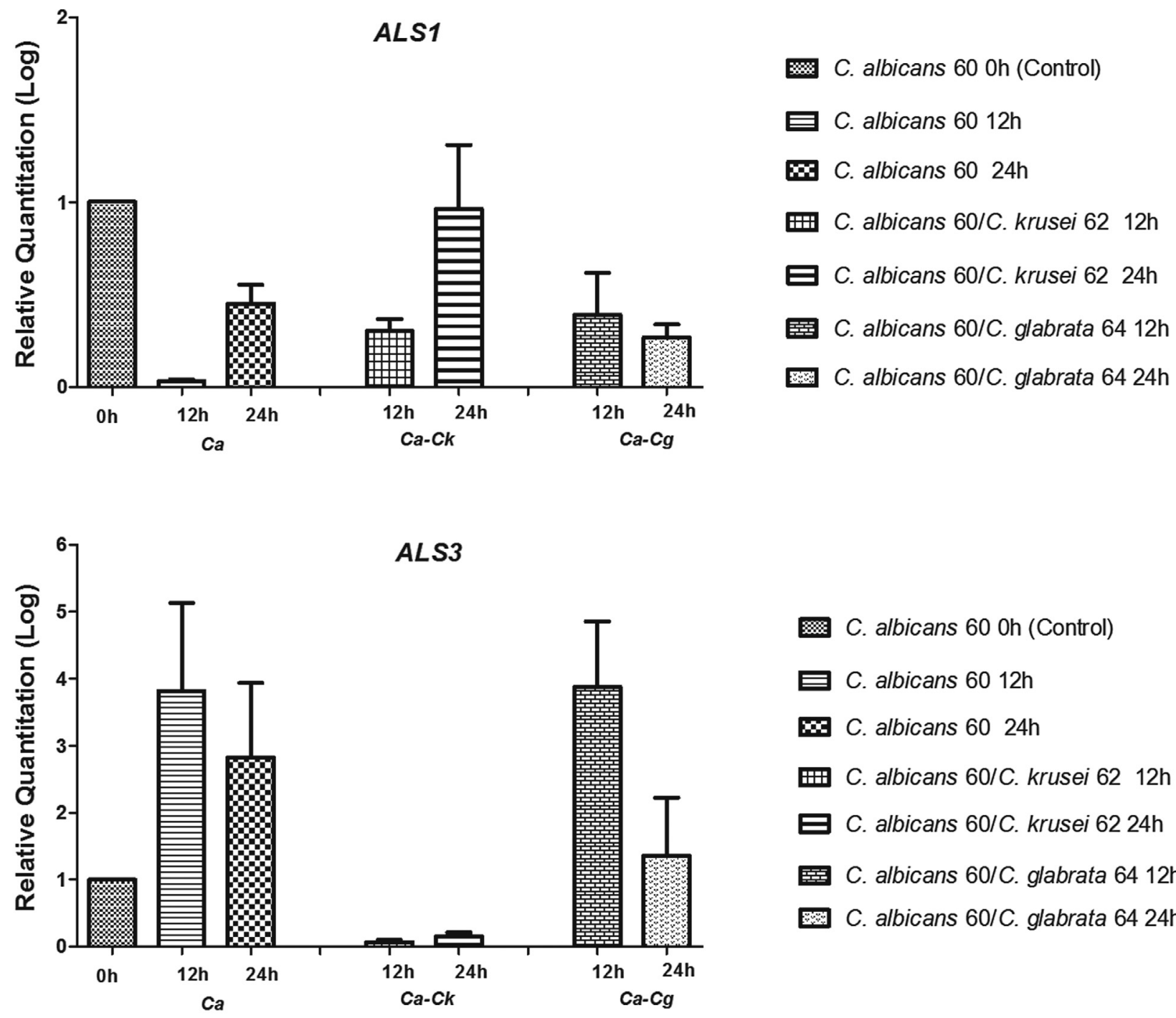

C. albicans 60 Oh (Control)

曰C. albicans $6012 \mathrm{~h}$

C. albicans $6024 \mathrm{~h}$

曲 C. albicans 60/C. krusei 62 12h

曰 C. albicans 60/C. krusei $6224 \mathrm{~h}$

㯰 C. albicans 60/C. glabrata $6412 \mathrm{~h}$

C. albicans 60/C. glabrata $6424 \mathrm{~h}$

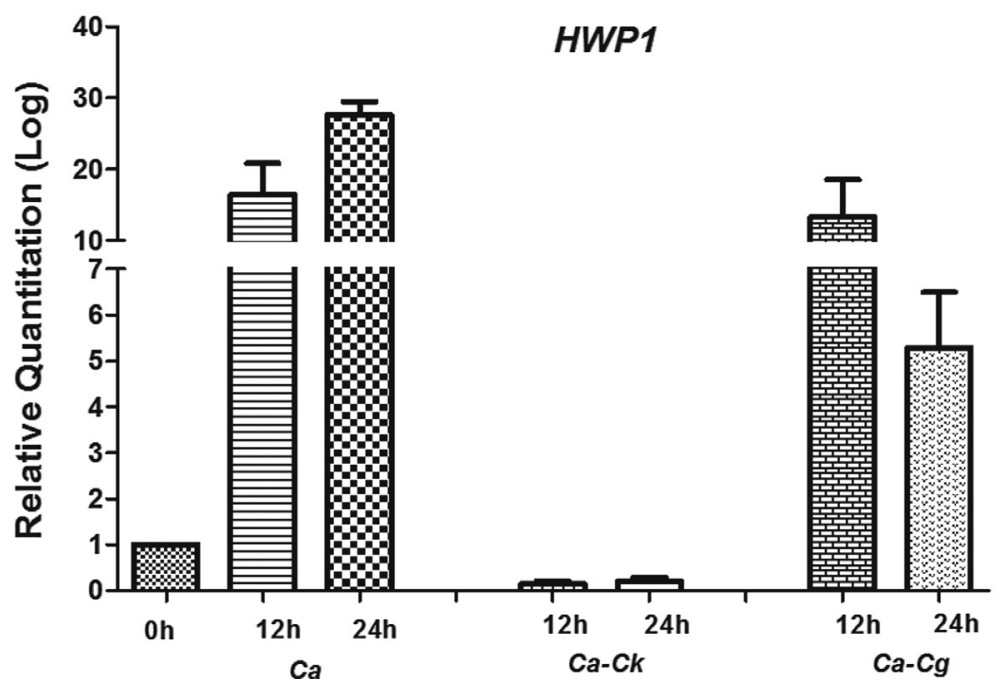

C. albicans 60 0h (Control)

曰 C. albicans $6012 \mathrm{~h}$

C. albicans $6024 \mathrm{~h}$

曲 C. albicans 60/C. krusei 62 12h

曰 C. albicans 60/C. krusei $6224 \mathrm{~h}$

圆 C. albicans 60/C. glabrata 64 12h

C. albicans 60/C. glabrata $6424 \mathrm{~h}$

Fig. 2. Relative quantification ( $\log$ ) of the expression of transcriptional regulatory genes (ALS1,ALS3 and HWP1) in C. albicans cells in monotypic and mixed biofilms at different development times using quantitative real-time PCR (qPCR), in relation to the control (time $0 \mathrm{~h}$ ). Values are expressed as the means and standard deviation. 

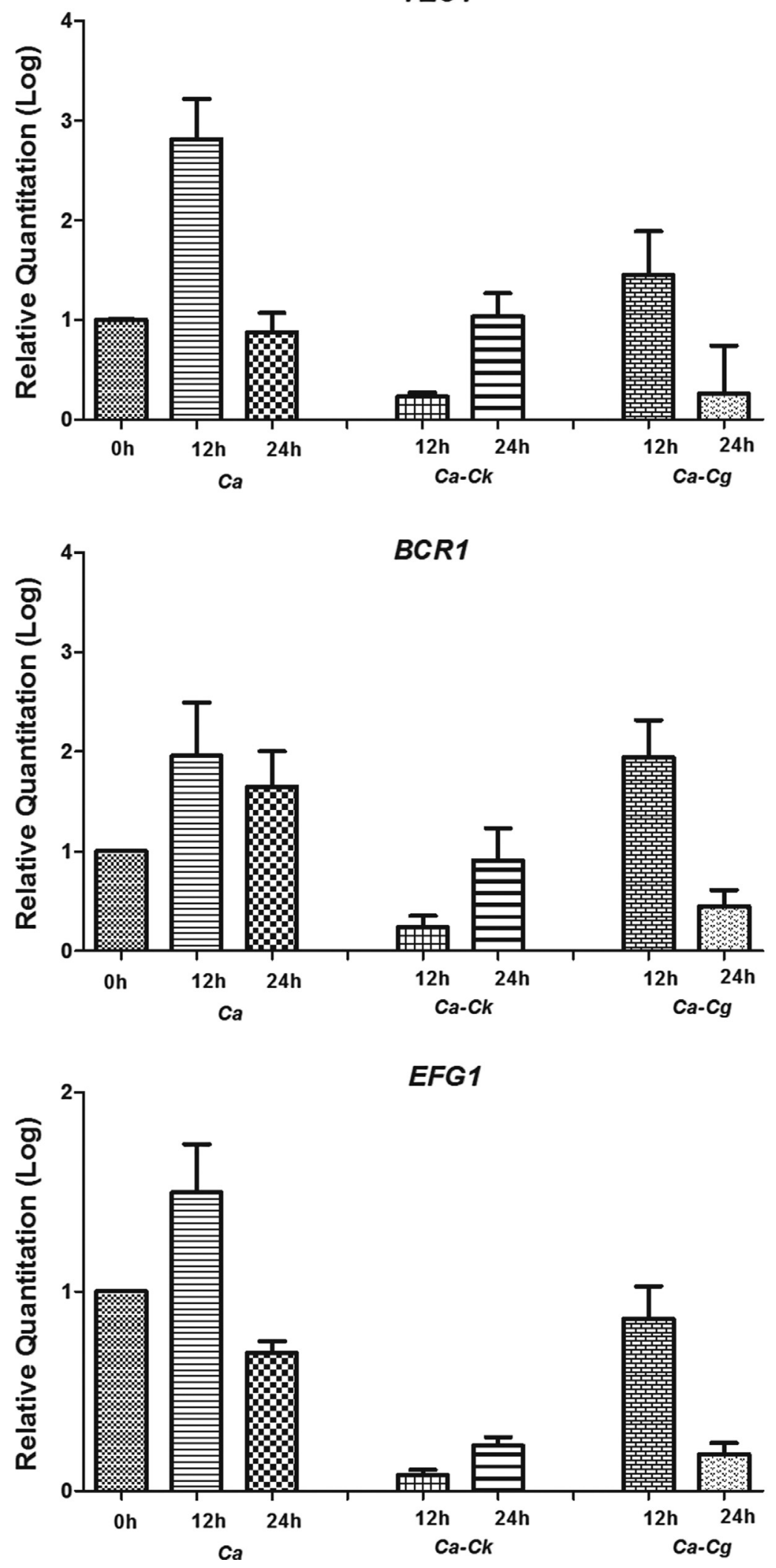

冈 C. albicans 60 Oh (Control)

ㅌ. albicans $6012 \mathrm{~h}$

B C. albicans $6024 \mathrm{~h}$

曲 C. albicans 60/C. krusei 62 12h

曰 C. albicans 60/C. krusei 62 24h

臣 C. albicans 60/C. glabrata 64 12h

C. albicans 60/C. glabrata $6424 \mathrm{~h}$
ॠ. albicans 60 0h (Control)

E C. albicans $6012 \mathrm{~h}$

B. C. albicans 60 24h

曲 C. albicans 60/C. krusei 62 12h

曰 C. albicans 60/C. krusei $6224 \mathrm{~h}$

目 C. albicans 60/C. glabrata 64 12h

C. albicans 60/C. glabrata $6424 \mathrm{~h}$
C. albicans 60 Oh (Control)

曰 C. albicans $6012 \mathrm{~h}$

C. albicans $6024 \mathrm{~h}$

曲 C. albicans 60/C. krusei 62 12h

曰C. albicans 60/C. krusei 62 24h

臣 C. albicans 60/C. glabrata $6412 \mathrm{~h}$

C. albicans 60/C. glabrata 64 24h

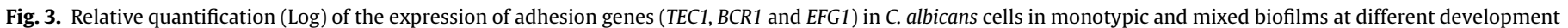
times using quantitative real-time PCR (qPCR), in relation to the control (time $0 \mathrm{~h}$ ). Values are expressed as the means and standard deviation. 


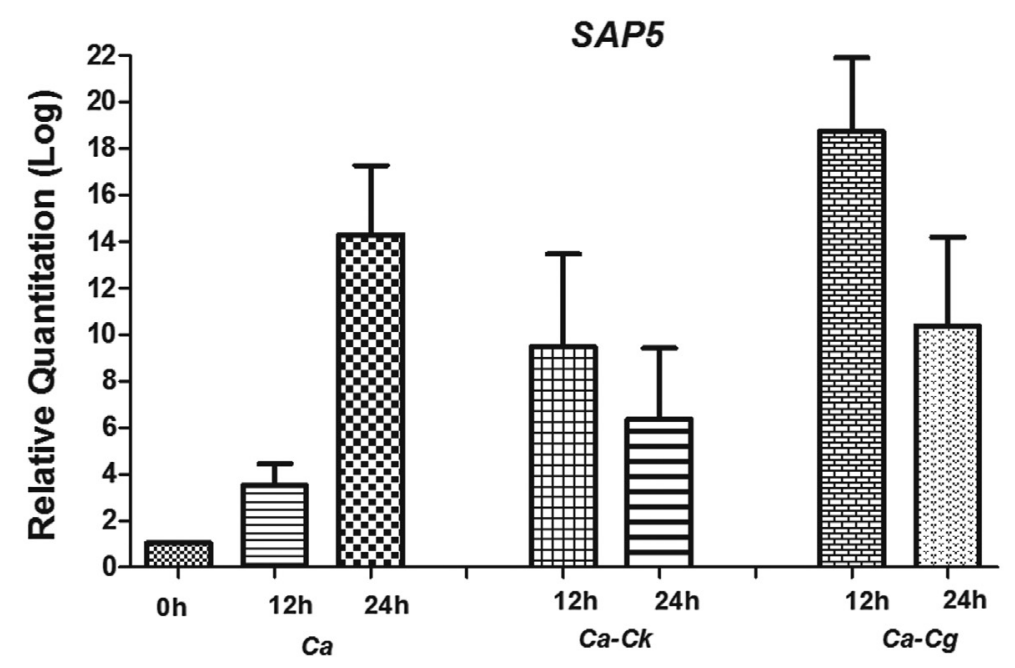

LIP9

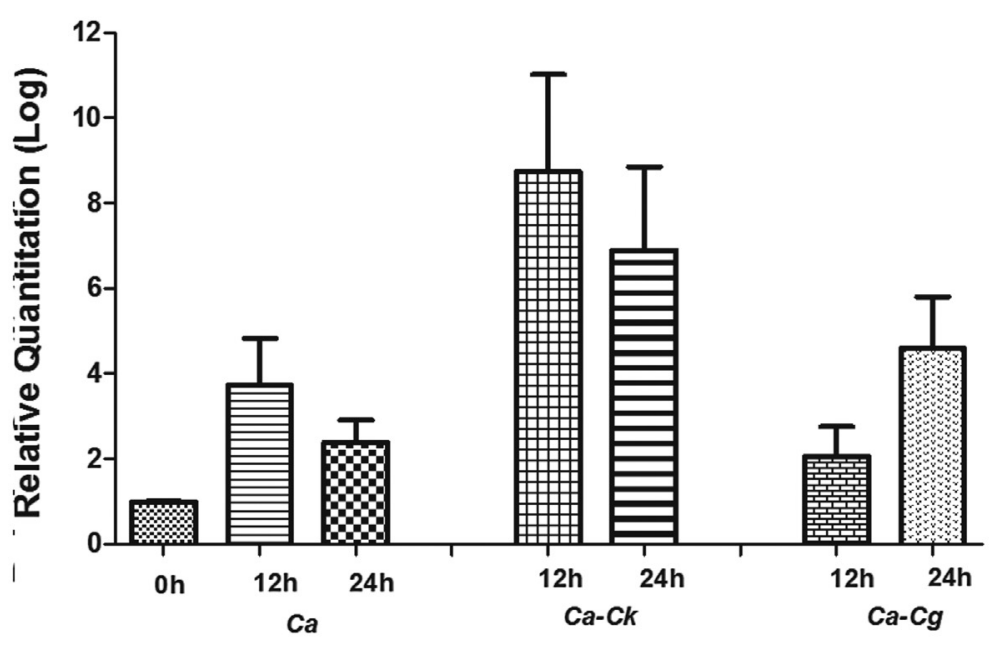

PLB2

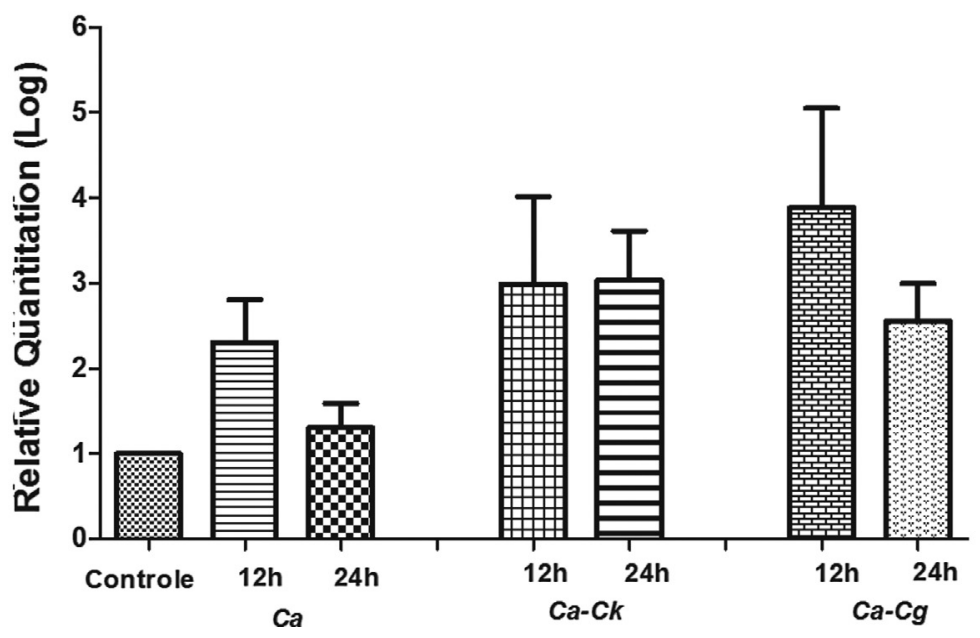

C. albicans 60 oh (Control)

C. albicans $6012 \mathrm{~h}$

C. albicans $6024 \mathrm{~h}$

C. albicans 60/C. krusei $6212 \mathrm{~h}$

曰 C. albicans 60/C. krusei $6224 \mathrm{~h}$

臣 C. albicans 60/C. glabrata $6412 \mathrm{~h}$

C. albicans $60 /$ C. glabrata $6424 \mathrm{~h}$
C. albicans 60 Oh (Control)

○. albicans $6012 \mathrm{~h}$

$\mathbf{B}$ C. albicans $6024 \mathrm{~h}$

曲 C. albicans 60/C. krusei $6212 \mathrm{~h}$

曰 C. albicans $60 / C$. krusei $6224 \mathrm{~h}$

覽 C. albicans 60/C. glabrata $6412 \mathrm{~h}$

C. albicans 60/C. glabrata $6424 \mathrm{~h}$

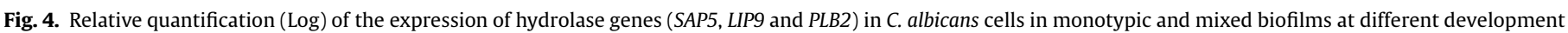
times using quantitative real-time PCR (qPCR), in relation to the control (time $0 \mathrm{~h}$ ). Values are expressed as the means and standard deviation.

reduction of $C$. albicans growth, in addition to inhibition of $C$. albicans filamentation.

Recently, our laboratory developed an in vivo study to evaluate the interactions of C. albicans (ATCC 18804) with C. krusei (ATCC
6258) and C. glabrata (ATCC 9030). Rossoni et al. (2015) demonstrated that $C$. albicans was able to establish competitive interactions with non-albicans species during infection development processes in different animal models. The authors 
demonstrated that inoculation of mixed suspensions of these yeasts in an invertebrate model of Galleria mellonella increased the survival rate of larvae for $96 \mathrm{~h}$ in relation to $C$. albicans suspension monotypic. Furthermore, monotypic suspensions of $C$. albicans induced lesions typical of oral candidiasis in immunocompromised mice, while the heterotypic suspensions were not capable to cause tissue damage and lesions in the oral cavity.

In the literature, several hypotheses have been proposed to explain this intriguing phenomenon of inhibition between these two species, such as competition for food and space, dissemination of inhibitory chemicals produced in the association and even the existence of mediators or molecular messengers that are able to reduce factors related to the virulence of $C$. albicans (Korres, Buss, Ventura, \& Fernandes, 2011; Rossoni et al., 2015; Thein et al., 2007).

Mixed biofilms with C. glabrata also showed decreased CFU/mL counts of $C$. albicans at 12 and $24 \mathrm{~h}$; however, there was a slight increase in the expression of the ALS3, HWP1, SAP5, PLB2 and LIP9 genes at 12 and $24 \mathrm{~h}$ and of TEC1 and BCR 1 at $12 \mathrm{~h}$. These results may suggest an ecologically neutral relationship or even one of synergism, as described by Pathak, Sharma, and Shrivastva (2012), who evaluated the in vitro interaction between these species and observed a positive relationship between them. In contrast, Silva et al. (2013) detected a neutral relationship between these species, in which the number of culturable cells of each species was not affected by the presence of the other. Furthermore, authors such as Cenci et al. (2008) have noted that C. albicans in a mixed biofilm with $C$. glabrata shows the same degree of growth as when studied in a monotypic biofilm. In contrast, Agwu et al. (2012) observed a decrease in the development of $C$. albicans hyphae in the presence of $C$. glabrata under some conditions tested.

The present study is a pioneer in the temporal assessment of C. albicans genes in the presence of C. krusei and C. glabrata. However, more complex studies contributing to a greater understanding and elucidation of the genetic and molecular mechanisms involved in the ecological relationships between Candida species are required to discover new alternative therapies for the treatment of local and systemic candidiasis.

\section{Conclusion}

Given the results presented herein, we can conclude that $C$. krusei and $C$. glabrata may alter or inhibit the mechanisms involved in the in vitro adhesion and formation of $C$. albicans biofilms, influencing the pathogenicity of this species and suggesting a competitive interaction with C. krusei and C. glabrata during biofilm formation.

\section{Conflict of interest}

There authors declare that there are no conflict of interests.

\section{Sources of funding}

São Paulo Council of Research-FAPESP, Brazil (Grants 2011/ 15194-0 and 2012/15250-0) for supporting this research.

\section{Ethical approval}

Approved by the Research Ethics Committee of the São José dos Campos School of Dentistry/UNESP (Protocol 051/2009-PH/CEP).

\section{Acknowledgment}

We acknowledge the São Paulo Council of Research-FAPESP, Brazil (Grants 2011/15194-0, 2012/15250-0 and 2012/02184-9) for supporting this research.

\section{Appendix A. Supplementary data}

Supplementary data associated with this article can be found, in the online version, at http://dx.doi.org/10.1016/j.archoralbio.2016. 01.005 .

\section{References}

Agwu, E., Ihongbe, J. C., McManus, B. A., Moran, G. P., Coleman, D. C., \& Sullivan, D. J. (2012). Distribution of yeast species associated with oral lesions in HIV-infected patients in Southwest Uganda. Medical Mycology, 50, 276-280.

Barros, L. M., Boriollo, M. F., Alves, A. C., Klein, M. I., Gonçalves, R. B., \& Höfling, J. F. (2008). Genetic diversity and exoenzyme activities of Candida albicans and Candida dubliniensis isolated from the oral cavity of Brazilian periodontal patients. Archives of Oral Biology, 53, 1172-1178.

Cenci, T. P., Deng, D. M., Kraneveld, E. A., Manders, E. M. M., Del Bel Cury, A. A., Cate, J M., et al. (2008). The effects of Streptococcus mutans and Candida glabrata on Candida albicans biofilms formed on different surfaces. Archives of Oral Biology, 53, 755-764.

Chandra, J., Kuhn, D. M., Mukherjee, P. K., Hoyer, L. L., McCormick, T., \& Ghannoum, M. A. (2001). Biofilm formation by the fungal pathogen Candida albicans: development, architecture, and drug resistance. Journal of Bacteriology, 183, 5385-5394.

Costa, A. C. B. P., Pereira, A. C., Freire, F., Junqueira, J. C., \& Jorge, A. O. C. (2013). Methods for obtaining reliable and reproducible results in studies of Candida biofilms formed in vitro. Mycoses, 56, 614-622.

El-Azizi, M. A., Starks, S. E., \& Khardori, N. (2004). Interactions of Candida albicans with other Candida spp. and bacteria in the biofilms. Journal of Applied Microbiology, 96, 1067-1073.

Fanning, S., \& Mitchell, A. P. (2012). Fungal biofilms. PLoS Pathogens, 8, e1002585.

Finkel, J. S., \& Mitchell, A. P. (2011). Genetic control of Candida albicans biofilm development. Nature Reviews Microbiology, 9, 109-118.

Hnisz, D., Bardet, A. F., Nobile, C. J., Petryshyn, A., Glaser, W., et al. (2012). A histone deacetylase adjusts transcription kinetics at coding sequences during Candida albicans morphogenesis. PLoS Genetics, 8, e1003118.

Hogan, D. A., Vik, A., \& Kolter, R. (2004). A Pseudomonas aeruginosa quorum-sensing molecule influences Candida albicans morphology. Molecular Microbiology, 54, $1212-1223$

Hube, B. (2004). From comensal to pathogen: stage-and tissue-specific gene expression of Candida albicans. Current Opinion in Microbiology, 7, 336-341.

Junqueira, J. C., Vilela, S. F. G., Rossoni, R. D., Barbosa, J. O., Costa, A. C. B. P., Rasteiro, V. M. C., et al. (2012). Oral colonization by yeasts in HIV-positive patients in Brazil Revista do Instituto de Medicina Tropical de São Paulo, 54, 17-24.

Kirkpatrick, W. R., Lopez-Ribot, J. L., McAtee, R. K., \& Patterson, T. F. (2000). Growth competition between Candida dubliniensis and Candida albicans under broth and biofilm growing conditions. Journal of Clinical Microbiology, 38, 902-904.

Korres, A. M., Buss, D. S., Ventura, J. A., \& Fernandes, P. M. (2011). Candida krusei and Kloeckera apis inhibit the causal agent of pineapple fusariosis, Fusarium guttiforme. Fungal Biology, 115, 1251-1258.

Livak, K. J., \& Schmittgen, T. D. (2001). Analysis of relative gene expression data using real-time quantitative PCR and the $2^{-\Delta \Delta C T}$ method. Methods, 25, 402-408.

Martin, R., Wächtle, B., Schaller, M., Wilson, D., \& Hube, B. (2011). Host-pathogen interactions and virulence-associated genes during Candida albicans oral infections. International Journal of Medical Microbiology, 301, 417-422.

Mayer, L. F., Wilson, D., \& Hube, B. (2013). Candida albicans pathogenicity mechanisms. Virulence, 4, 119-128.

Morales, D. K., \& Hogan, A. D. (2010). Candida albicans interactions with bacteria in the context of human health and disease. PLoS Pathogens, 6, e1000886.

Murciano, C., Moyes, D. L., Runglall, M., Tobouti, P., Islam, A., Hoyer, L. L., et al. (2012) Evaluation of the role of Candida albicans agglutinin-like sequence (Als) proteins in human oral epithelial cell interactions. PLoS One, 7, e33362.

Naglik, J. R., Rodgers, C. A., Shirlaw, P. J., Dobbie, J. L., Fernandes-Naglik, L. L., Greenspan, D., et al. (2003). Differential expression of Candida albicans secreted aspartyl proteinase and phospholipase B genes in human correlates with active oral and vaginal infections. Journal of Infectious Diseases, 188, 469-479.

Nailis, H., Coenye, T., Van Nieuwerburgh, F., Deforce, D., \& Nelis, H. J. (2006). Development and evaluation of different normalization strategies for gene expression studies in Candida albicans biofilms by real-time PCR. BMC Molecular Biology, 7, 25.

Nailis, H., Kucharíková, S., Ričicová, M., Van Dijck, P., Deforce, D., Nelis, H., et al. (2010). Real- time PCR expression profiling of genes encoding potential virulence factors in Candida albicans biofilms: identification of modeldependent and -independent gene expression. BMC Microbiology, 10, 114.

Nobile, C. J., \& Mitchell, A. P. (2006). Genetics and genomics of Candida albicans biofilm formation. Cellular Microbiology, 8, 1382-1391.

Park, S. J., Han, K. H., Park, J. Y., Choi, S. J., \& Lee, K. H. (2014). Influence of bacterial presence on biofilm formation of Candida albicans. Yonsei Medical Journal, 55, 449-458.

Pathak, A. K., Sharma, S., \& Shrivastva, P. (2012). Multi-species biofilm of Candida albicans and non albicans species on acrylic substrate. Journal of Applied Oral Science, 20, 70-75.

Rossoni, R. D., Barbosa, J. O., Vilela, S. F. G., Santos, J. D., Barros, P. P., Prata, M. C. D. A. et al. (2015). Competitive interactions between C. albicans, C.glabrata and C. 
krusei during biofilm formation and development of experimental candidiasis. PLoS One, 10(7), e0131700. http://dx.doi.org/10.1371/journal.

Samaranayake, L. P., MacFarlane, T. W., \& Williamson, M. I. (1987). Comparison of sabouraud dextrose and Pagano-Levin agar media for detection and isolation of yeasts from oral samples. Journal of Clinical Microbiology, 25, 162-164.

Samaranayake, L. P. (2006). Fungi of relevance to dentistry, Essential microbiology for dentistry. 3rd ed. Edinburgh, UK: Churchill Livingstone177-183.

Seneviratne, C. J., Silva, W. J., Jin, L. J., Samaranayake, Y. H., \& Samaranayake, L. P. (2009). Architectural analysis, viability assessment and growth kinetics of Candida albicans and Candida glabrata biofilms. Archives of Oral Biology, 54, $1052-1060$.

Silva, S., Pires, P., Monteiro, D. R., Negri, M., Gorup, L. F., Camargo, E. R., et al. (2013). The effect of silver nanoparticles and nystatin on mixed biofilms of Candida glabrata and Candida albicans on acrylic. Medical Mycology, 51, 178-184.
Thein, Z. M., Samaranayake, Y. H., \& Samaranayake, L. P. (2007). Characteristics of dual species Candida biofilms on denture acrylic surfaces. Archives of Oral Biology, 52, 1200-1208.

Thein, Z. M., Seneviratne, C. J., Samaranayake, Y. H., \& Samaranayake, L. P. (2009). Community lifestyle of Candida in mixed biofilms: a mini review. Mycoses, 52, 467-475.

Wächtler, B., Wilson, D., Haedicke, K., Dalle, F., \& Hube, B. (2001). From attachment to damage: defined genes of Candida albicans mediate adhesion, invasion and damage during interaction with oral epithelial cells. PLoS One, 6, e17046.

Zordan, R., \& Cormack, B. (2012). Adhesins on opportunistic fungal pathogens. In R. A. Calderone, \& C. J. Clancy (Eds.), Candida and candidiasis (pp. 243-259).ASM Press. 